\title{
Possible role of acetylcholine in regulating spatial novelty effects on theta rhythm and grid cells
}

\author{
Caswell Barry ${ }^{1,2 *}$, James G. Heys ${ }^{1}$ and Michael E. Hasselmo ${ }^{1 *}$ \\ Department of Psychology, Center for Memory and Brain, Boston University, Boston, MA, USA \\ 2 Institute of Neurology, University College London, London, UK
}

\author{
Edited by: \\ Lisa M. Giocomo, Norwegian \\ University of Science and \\ Technology, Norway \\ Reviewed by: \\ Dori Derdikman, Technion, Israel \\ James Ainge, University of \\ St Andrews, UK \\ *Correspondence: \\ Caswell Barry, ICN, Alexandra \\ House, 17 Queen Square, WC1N \\ 3AR, London, UK. \\ e-mail: caswell.barry@ucl.ac.uk \\ Michael E. Hasselmo, Department \\ of Psychology, Center for Memory \\ and Brain, Boston University, \\ Boston, 02215 MA, USA. \\ e-mail: hasselmo@bu.edu
}

Existing pharmacological and lesion data indicate that acetylcholine plays an important role in memory formation. For example, increased levels of acetylcholine in the hippocampal formation are known to be associated with successful encoding while disruption of the cholinergic system leads to impairments on a range of mnemonic tasks. However, cholinergic signaling from the medial septum also plays a central role in generating and pacing theta-band oscillations throughout the hippocampal formation. Recent experimental results suggest a potential link between these distinct phenomena. Environmental novelty, a condition associated with strong cholinergic drive, has been shown to induce an expansion in the firing pattern of entorhinal grid cells and a reduction in the frequency of theta measured from the LFP. Computational modeling suggests the spatial activity of grid cells is produced by interference between neuronal oscillators; scale being determined by theta-band oscillations impinging on entorhinal stellate cells, the frequency of which is modulated by acetylcholine. Here we propose that increased cholinergic signaling in response to environmental novelty triggers grid expansion by reducing the frequency of the oscillations. Furthermore, we argue that cholinergic induced grid expansion may enhance, or even induce, encoding by producing a mismatch between expanded grid cells and other spatial inputs to the hippocampus, such as boundary vector cells. Indeed, a further source of mismatch is likely to occur between grid cells of different native scales which may expand by different relative amounts.

Keywords: grid cell, place cell, acetylcholine, theta, stellate cell

\section{INTRODUCTION}

Compelling evidence from several fields indicates that acetylcholine enhances the dynamics of memory encoding. Pharmacological studies in humans, primates, and other animals show that blockade of cholinergic receptors compromises memory formation whereas cholinergic agonists can promote mnemonic function. In particular, impairment of the parahippocampal cholinergic system produces deficits in recognition, spatial, and working memory apparently limited to encoding but not retrieval (Aigner and Mishkin, 1986; Tang et al., 1997). Electrophysiological investigations suggest this enhancement is due to several factors including an augmentation of long-term potentiation (LTP) as well as suppression of feedback connectivity, which may reduce interference between existing memories and incoming stimuli (Hasselmo et al., 1995; Hasselmo, 2006). However, a parallel body of work implicates acetylcholine in the generation and pacing of theta-band oscillations observed in the local field potential (LFP) throughout the hippocampal formation. For example, disruption of cholinergic transmission from the medial septum to the hippocampus severely attenuates theta power (Lee et al., 1994), impairs spatial learning (Rogers and Kesner, 2003; Elvander et al., 2004) [but also see Baxter et al. (1995)], and reduces the spatial specificity of hippocampal place cells (Shapiro et al., 1989; Brazhnik et al., 2003). Conversely systemic application of physostigmine, which leads to elevated levels of acetylcholine, promotes a constant theta state in the LFP of anesthetized animals (Yoder and Pang, 2005).

The significance of this dual role exhibited by acetylcholine remains unclear; to what extent are common systems involved and what role might modulation of theta-band oscillations have in memory encoding? A recent theory linking theta-band frequencies of intrinsic oscillations in entorhinal stellate cells with the generation of spatial firing produced by grid cells provides a potential resolution. Briefly, the scale of the grid firing pattern is believed to depend on the relative frequency of theta-band neuronal oscillators in the entorhinal cortex (Burgess et al., 2007), which are subject to cholinergic modulation. In response to environmental novelty, a condition known to increase intrahippocampal acetylcholine, the frequency of the theta-band network oscillations is seen to decrease (Jeewajee et al., 2008b) and is matched by an increase in grid scale (Barry et al., Soc. Neurosci. Abstr. 101.25, 2009). We anticipate the expansion of the grid firing pattern will likely lead to a mismatch between grids and other spatial inputs to the hippocampus [see also, (Burgess et al., 2007; Burgess, 2008)] and potentially also between grids of different native scales (Monaco and Abbott, 2011). It is likely then that this orthogonalized input promotes the formation of spatial memories in the form of distinct, stable place cell representations. In this document we first describe how acetylcholine has been proposed to modulate learning in the hippocampal formation before 
focusing on its role in the generation of theta. Finally, we argue that the reduction in theta frequency observed in response to environmental novelty is mediated by acetylcholine and drives hippocampal remapping.

\section{ACETYLCHOLINE AND ITS ROLE IN THE MODULATION OF LEARNING}

Extensive data indicates a role of acetylcholine in encoding of new memories. Multiple studies have shown impairments of encoding after systemic injections of scopolamine, an antagonist at muscarinic acetylcholine receptors. Subjects that encoded a list of words under the influence of scopolamine showed severe reductions in subsequent free recall of the word list (Ghoneim and Mewaldt, 1975; Peterson, 1977). The same subjects under the influence of scopolamine did not show impaired retrieval of words encoded before the injection. Scopolamine injections also impair performance in an n-back working memory task (Green et al., 2005). In monkeys, the encoding of visual stimuli for subsequent recognition is impaired by systemic injections of scopolamine (Aigner and Mishkin, 1986), and in rats systemic injections of muscarinic antagonists impair performance on the Morris water maze (Whishaw, 1985; Buresova et al., 1986) and eight-arm radial maze (McGurk et al., 1988).

\section{CHOLINERGIC MODULATION IN THE HIPPOCAMPAL FORMATION}

Localized infusions suggest that these effects of acetylcholine receptor blockade are due to effects in the hippocampus and regions of parahippocampal cortex. Encoding for recognition memory in monkeys is impaired by local infusions of scopolamine into the perirhinal cortex but not the dentate gyrus (Tang et al., 1997). In rats, local infusions of scopolamine into the perirhinal cortex impair encoding of stimuli for subsequent recognition (Winters et al., 2006), and local infusions of cholinergic antagonists impair encoding of the association between tone stimuli and shock in a trace conditioning paradigm (Bang and Brown, 2009; Esclassan et al., 2009). Encoding of platform location in the Morris water maze is impaired by infusions of scopolamine in the hippocampus (Blokland et al., 1992) and the medial septum (Elvander et al., 2004). Encoding for subsequent recognition is also impaired by selective lesions of the cholinergic fibers in rats that innervate entorhinal cortex (McGaughy et al., 2005) and perirhinal cortex (Winters and Bussey, 2005) and recognition performance is also impaired by selective lesions of cholinergic fibers innervating perirhinal cortex in monkeys (Turchi et al., 2005).

The role of acetylcholine in the encoding of new information appears consistent with microdialysis studies of levels of acetylcholine in the hippocampus, which increase in novel environments (Acquas et al., 1996). Acetylcholine levels in the hippocampus and neocortex also increase during active exploration of the environment (Marrosu et al., 1995). Active exploration is also associated with theta rhythm oscillations in the hippocampus, and theta rhythm oscillations are associated with increases in acetylcholine levels measured with microdialysis (Monmaur et al., 1997) and amperometry (Zhang et al., 2010). The increase of acetylcholine during novelty is consistent with the evidence that cholinergic lesions appear to impair the increased exploration by rats encountering novel objects (Winters and Bussey, 2005) or novel associations of locations and context (Easton et al., 2011) though surprisingly not more complex episodic associations. In summary, the studies of local infusion effects and selective cholinergic lesions suggest a role for acetylcholine in the hippocampus and parahippocampal cortex for encoding of new memories. Further understanding of these behavioral effects can be obtained by considering the cellular effects of acetylcholine on neurons within these cortical structures.

\section{CHOLINERGIC MODULATION OF SYNAPTIC AND CELLULAR MECHANISMS FOR ENCODING}

Acetylcholine could enhance encoding through a number of direct effects on the physiology of cortical principal cells. Acetylcholine directly enhances the induction of LTP in cortical regions including the hippocampus (Blitzer et al., 1990), the entorhinal cortex (Yun et al., 2000), and other structures including piriform cortex (Patil et al., 1998) and primary visual cortex (Brocher et al., 1992). The induction of Hebbian synaptic modification could also be enhanced by muscarinic enhancement of postsynaptic spiking activity due to direct depolarization of cortical pyramidal cells (Cole and Nicoll, 1984; Barkai and Hasselmo, 1994) as well as suppression of spike frequency accommodation (Madison and Nicoll, 1984; Madison et al., 1987; Barkai and Hasselmo, 1994).

Acetylcholine may also enhance encoding by augmenting the influence of external afferent input relative to the internal spread of activity within cortical structures (see Figure 1). Acetylcholine causes direct nicotinic enhancement of afferent fiber synaptic transmission at thalamocortical synapses (Gil et al., 1997). Acetylcholine also enhances the response of the dentate gyrus to afferent input (Foster and Deadwyler, 1992), and these responses also increase during behavioral states associated with increased acetylcholine such as REM sleep (Winson and Abzug, 1977). At the same time as it enhances input, acetylcholine reduces the synaptic transmission at excitatory glutamatergic recurrent feedback synapses within cortical structures. For example,

FIGURE 1 I Effect of acetylcholine on cortical processing. High
acetylcholine (ACh) enhances encoding by increasing the efficacy of
afferent input to the cortex via the action of nicotinic receptors. At the same
time high acetylcholine suppresses transmission at glutamatergic recurrent
feedback synapses within cortical regions. Conversely, lower acetylcholine
favors the retrieval of stored memories by enhancing the influence of
recurrent connections relative to afferent input.


acetylcholine suppresses excitatory feedback synapses in the piriform cortex (Hasselmo and Bower, 1992, 1993), in neocortical structures (Gil et al., 1997; Kimura and Baughman, 1997) and in region CA3 of the hippocampal formation (Hasselmo et al., 1995; Vogt and Regehr, 2001; Kremin and Hasselmo, 2007). Computational models of cortical structures show that this selective muscarinic presynaptic inhibition of glutamatergic synaptic transmission prevents retrieval of previously encoded memories from interfering with the encoding of new memories in the hippocampus (Hasselmo et al., 1992; Hasselmo and Schnell, 1994), while the cholinergic enhancement of input and LTP can enhance encoding.

In contrast, cortical circuits have different dynamics during slow wave sleep, when levels of acetylcholine in the hippocampus and neocortex drop to less than $1 / 3$ of waking levels (Marrosu et al., 1995). Slow wave sleep has been proposed to provide dynamics for consolidation of previously encoded information (Buzsaki, 1989; Wilson and McNaughton, 1994). The lower levels of acetylcholine mean less presynaptic inhibition of glutamatergic transmission, allowing the spread of activity at feedback synapses within the hippocampus and from hippocampus back to neocortical structures (Hasselmo, 1999). Consistent with this, scopolamine blockade of acetylcholine enhances consolidation (Rasch et al., 2006) whereas cholinergic agonists impair consolidation in rats (Bunce et al., 2004) and humans (Gais and Born, 2004).

\section{MAINTENANCE OF BISTABLE PERSISTENT SPIKING AT THE LEVEL OF INPUTS TO HIPPOCAMPUS}

In addition to enhancing dynamics for encoding, acetylcholine also appears to be important for the maintenance of working memory (Green et al., 2005). This is consistent with cellular effects of acetylcholine that enhance the maintenance of presented activity by enhancing bistable persistent spiking or plateau potentials (Klink and Alonso, 1997) that allows depolarization to persist after the end of an input stimulus. In addition to enhancing mechanisms of working memory, these effects may also favor long-term encoding by prolonging specific input patterns to the hippocampus, acting as a buffer to hold recently presented novel information during encoding (Hasselmo, 2006; Hasselmo and Stern, 2006).

The effects described above provide a coherent framework for understanding the enhancement of encoding. However, they focus on a static view of the role of acetylcholine in the hippocampal formation, as if the representations for working memory and long-term encoding were all stable fixed-point attractors. To fully understand the role of acetylcholine, we must address the full range of dynamics, including transient activity and oscillations. Acetylcholine also has a well-defined role in the generation and pacing of theta, which is itself linked to memory formation.

\section{HIPPOCAMPAL THETA}

Theta-band modulations of the LFP are among the most distinct and easily visualized electrophysiological phenomena in the brain. In the moving rat theta is evident in the hippocampus as a large amplitude (exceeding $1 \mathrm{mV}$ ) 6-12 Hz sinusoidal oscillation (Vanderwolf, 1969, 1971; Buzsaki, 2002) (see Figure 2A).
Though less obvious, theta is also present in the hippocampal LFP of other animals including bats, rabbits, and humans (Winson, 1976; Kahana et al., 1999; Cantero et al., 2003; Ulanovsky and Moss, 2007). Work conducted in the 1960s and 1970s revealed that theta has distinct behavioral correlates which vary between animal species, as does the frequency and amplitude of the oscillation (Whishaw and Vanderwolf, 1973; Vanderwolf, 2001). These correlates are most clearly defined for the rat in which, based on behavioral and pharmacological grounds, two distinct forms of theta have been identified (Kramis et al., 1975; Vanderwolf et al., 1977). Type 1 theta, sometimes referred to as translational theta or $t$-theta, is apparent during voluntary movement, specifically any behavior that causes the animal's head to move through space (e.g., running, swimming, grooming) (Whishaw and Vanderwolf, 1973; O'Keefe and Nadel, 1978). In contrast, type 2 or attentional theta, can be identified during highly aroused states when the animal is immobile (e.g., in the presence of a predator or during fear conditioning) (Whishaw, 1972; Sainsbury et al., 1987).

While several subcortical nuclei are implicated in the pacing of theta, the medial septum-diagonal band of Broca seems particularly important and is necessary for the generation of both forms of theta; inactivation or lesion of the medial septum abolishes all theta (Rawlins et al., 1979; Mitchell et al., 1982; Mizumori et al., 1989). Pharmacological manipulation of the medial septum has revealed distinct neuromodulatory mechanisms supporting the two forms (Bland, 1986; Mizumori et al., 1990b). Hence, type 2 theta appears to be acetylcholine dependent, so intraseptal infusion of anti-cholinergic drugs, such as atropine, eliminate it but spare the acetylcholine independent type 1 theta (Kramis et al., 1975). Conversely, application of carbachol, a cholinergic agonist, to the septum promotes a constant type 2 theta state (Bunce et al., 2004). In turn, movement-related type 1 theta depends upon the entorhinal cortex as entorhinal lesions spare only type 2 theta (Kramis et al., 1975). In particular the glutamatergic layer II/III entorhinal afferents to the hippocampus seem to be a necessary component of the circuit generating movement-related theta; application of the NMDAR antagonist ketamine abolishes type 1 theta and coupled with scopolamine removes all theta (Buzsaki, 2002). Electrophysiological investigation of the medial septum revealed populations of GABAergic and cholinergic neurons, which exhibit phase locking to hippocampal theta, and project to interneurons in CA3 and CA1 (Freund and Antal, 1988; Stewart and Fox, 1990; King et al., 1998). Destruction of the cholinergic projections alone attenuates but does not eliminate theta during movement and as such is the complement of septal infusion of cholinergic antagonists (Lee et al., 1994). It is tempting then to simply equate these two cell types with the two forms of theta (Stewart and Fox, 1990). However, subsequent work has complicated the picture. For example, while the GABAergic septal cells are highly active and show strong theta phase locking, the cholinergic cells are less active and do not exhibit rhythmic activity (Simon et al., 2006). Furthermore, work in slices shows the application of cholinergic agonists to the hippocampus, in particular CA3, is sufficient to promote spontaneous oscillations (Fischer et al., 1999). Similarly, in the intact rat, non-phasic activation of acetylcholine receptors in the hippocampus and medial septum increases theta 
A

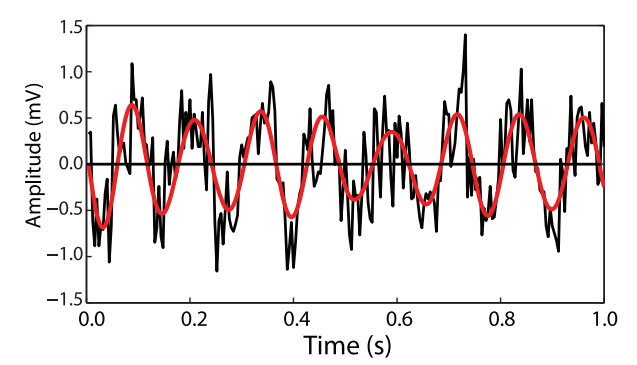

C

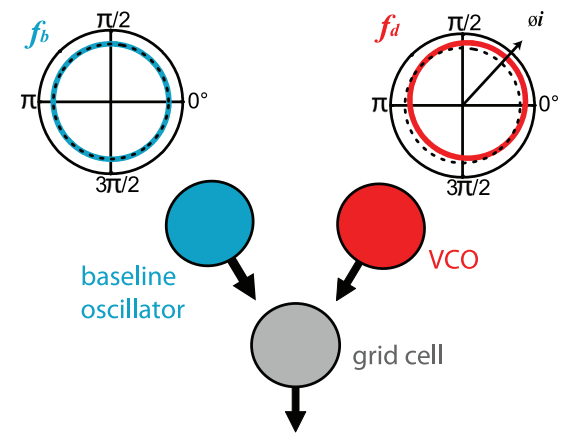

B

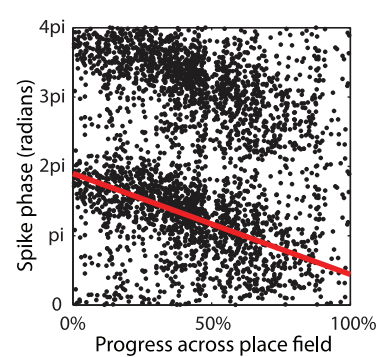

D Run in prefered direction (øi)

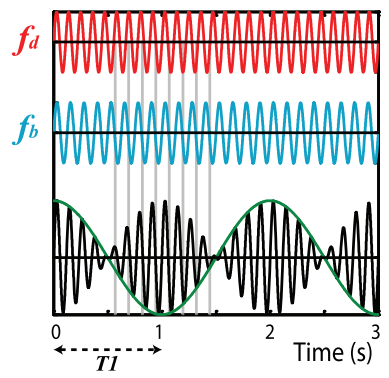

E

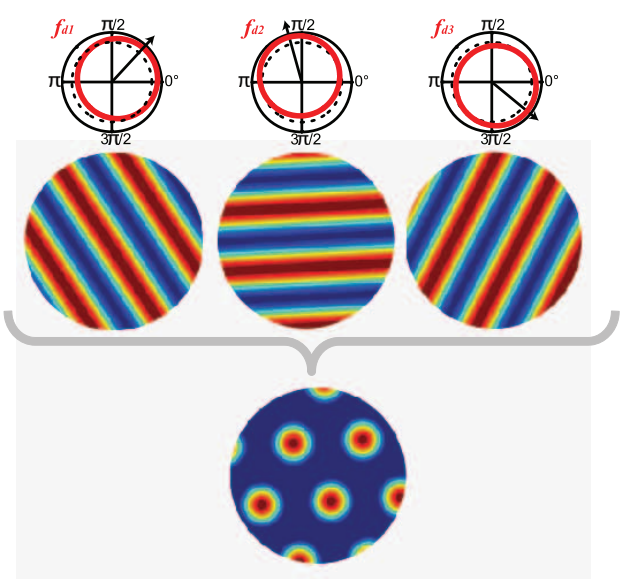

FIGURE 2 | Theta-band oscillations play an important role in structuring spatial activity in the hippocampus and entorhinal cortex. (A) Theta recorded from the entorhinal LFP of a moving rat. Black trace, raw LFP, mean normalized showing $1 \mathrm{~s}$ of data. $8 \mathrm{~Hz}$ theta modulation is clearly visible, higher frequency gamma oscillations are also present. Red trace, same signal band pass filtered in 6-12 $\mathrm{Hz}$ range. (B) Phase precession in a CA1 place cell, the phase, and location of individual spikes is shown as follows: $X$-axis indicates the animal's progress across the place field, moving left to right. Y-axis indicates the phase of each spike relative to theta measured from the cell layer, two cycles are shown for completeness. Red line indicates best fit to data for linear-circular regression. (C) Schematic of the basic oscillatory interference model showing two components: a baseline oscillation (blue) with a constant frequency in the theta-band ( $f b)$ and; A velocity controlled component (red) the frequency $(f d)$ of which increases proportionate to the animal's velocity in a preferred direction $(\varphi i)$. (D) Interference pattern generated between the components described in C. Spikes are emitted at the peaks of the carrier (black) which has a frequency equal to the mean of $f b$ and $f d$. Grid scale is determined by the envelope (green) which has a frequency equal to the difference between $\mathrm{fb}$ and $\mathrm{fd}$. (E) Multiple velocity controlled components with preferred firing directions at increments of $60^{\circ}$ are required to produce a grid interference pattern. A single baseline oscillator and velocity controlled component will produce a spatially stable stripped pattern similar to a sine grating. power (Siok et al., 2006). A more accurate view then is that the GABAergic septal cells probably do function as a pacemaker, and so entrain oscillators in the EC and hippocampus. In contrast, the cholinergic projection has a permissive modulatory role (Buzsaki, 2002).
What then is the function of hippocampal theta? In addition to the behavioral correlates outlined above, manipulations that attenuate or abolish theta in vivo point to a role in learning and memory. Lesions made to the fornix or septum, which reduce theta power but also cholinergic drive to the hippocampus, impair 
performance on a wide range of memory tasks including goal directed navigation (Winson, 1978; Hagan et al., 1988), delayed non-match to position (Markowska et al., 1989), and spatial alternation (Givens and Olton, 1990). More specifically, reversible medial septal inactivations show that the deficit is specific to the encoding and retrieval phases of a spatial alternation task, thus theta was not required for maintenance of a recent memory (Mizumori et al., 1990a). Similarly, theta power was found to correlate with performance on a non-spatial working memory task but not on a reference memory task, indicating a role in encoding of information (Givens and Olton, 1994). This behavioral link between theta and learning is supported by physiological studies that point to a modulation in the efficacy of hippocampal LTP with theta phase. As such, tetanic stimuli arriving at the peak of theta measured in the stratum radiatum (corresponding to trough of theta at the fissure), are more likely to result in potentiation, those arriving during the opposite phase produce depression (Huerta and Lisman, 1995; Holscher et al., 1997; Orr et al., 2001; Hyman et al., 2003). Theta can also provide a mechanism during which synaptic potentiation or synaptic depression can occur depending upon relative timing of the presynaptic input and separate modulatory input (Kwag and Paulsen, 2009). In this study, CA1 Schaeffer collaterals were stimulated relative to an induced theta input at the cell body. Either LTP or LTD could be induced in the Schaeffer collaterals depending upon which phase of theta the stimulation occurred and the relative timing of secondary stimulation of the tempero-ammonic pathway. This work highlights the fact that the hippocampus and entorhinal circuit must work in concert with theta to produce consistent learning rules.

\section{THETA-BAND MODULATION OF SPATIAL FIRING IN THE HIPPOCAMPUS: PLACE CELLS AND GRID CELLS}

Perhaps the clearest evidence for the functional role of theta comes from studies of the spatially modulated cell types found in the hippocampus and surrounding regions; in these areas at least, theta-band oscillations seem to have an important role in structuring spatial activity. Working in the early 1970s O'Keefe and Dostrovsky (1971) first reported place cells, hippocampal pyramidal cells that exhibit spatially stable firing. Place cells seem to be a common feature of the mammalian hippocampus and have subsequently been found in bats, monkeys, humans, and even pigeons (Ekstrom et al., 2003; Hori et al., 2003; Bingman et al., 2006; Ulanovsky and Moss, 2007). In a familiar environment the firing field (place field) of a place cell is typically stable between visits to a location, even if those visits are separated by several days (Muller et al., 1987). However, if an animal is moved to a novel environment place cells change their relative firing positions and rates such that a new stable population code is generated, this effect is known as remapping and is considered to be part of the process by which the hippocampus encodes a new spatial memory (O'Keefe and Nadel, 1978; Muller and Kubie, 1987; Bostock et al., 1991). The timing of spikes emitted by place cells show an interesting relationship relative to the current phase of theta measured from the LFP, as follows: when an animal first enters the firing field of a cell, action potentials are emitted around the peak of theta (measured from the pyramidal cell layer). As the animal advances through the field spikes are emitted at progressive earlier phases, typically moving forwards by about $180^{\circ}$ during a single run to be fired near the trough of theta as it exits the place field (O'Keefe and Recce, 1993) (see Figure 2B). This effect, known as phase precession, is equivalent to the spike train of the place cell being modulated at a frequency slightly greater than theta measured from the LFP (as measured in autocorrelations); this modulation is referred to as the intrinsic firing frequency of the cell. Because spike phase is linked to the proportion of the field traversed, cells with large place fields tend to have lower frequency modulation than those with smaller fields and similarly faster running is matched by higher firing frequencies (Huxter et al., 2003; Geisler et al., 2007). Phase precession is clearest for runs made on a linear track, in such conditions the phase of spikes relative to theta convey more information about the animal's position than the firing rate (Jensen and Lisman, 2000; Huxter et al., 2003). Phase precession is, however, evident in data collected during open field foraging (Burgess et al., 1994; Skaggs et al., 1996).

Recently a second class of spatial cells, grid cells, have been reported in the medial entorhinal cortex of rodents and humans, as well as in the pre and parasubiculum (Fyhn et al., 2004; Hafting et al., 2005; Boccara et al., 2010; Doeller et al., 2010). Grid cells, like place cells, have spatially stable fields but differ in that each grid cell has multiple circular firing fields arranged in a hexagonal lattice. Grid cells that neighbor each other in the brain typically exhibit a lattice of similar scale but a topographical gradient exists so those at more ventral locations tend to be of a larger scale, increasing in increments that possibly have a fixed ratio (Hafting et al., 2005; Barry et al., 2007; Stensland et al., 2010). The lattice of grids in each hemisphere, and possibly those in different hemispheres, appear to have the same orientation such that the hexagonal arrangement of their firing fields share the same three axes, albeit with some localized distortions (Hafting et al., 2005; Barry et al., 2007; Stensland et al., 2010). Significantly grid cells also exhibit phase precession, the effect being clearest in cells recorded from layer II of medial entorhinal cortex where all grids precess. In deeper layers a subset of grid cells phase precess, the others being phase locked or simply firing with no apparent relationship to theta phase (Hafting et al., 2008).

\section{THE OSCILLATORY INTERFERENCE MODEL OF GRID CELL FIRING}

The regular firing of grid cells is particularly amenable to computational modeling and a number of ideas have been presented to account for the lattice-like activity of these cells. With a few exceptions [see Kropff and Treves (2008)] most of the models describe grid firing in terms of self-motion; updating an animal's representation of its location based on movement cues. Broadly, the models fall into two schools, those in which grid firing is a product of attractor dynamics (Fuhs and Touretzky, 2006; McNaughton et al., 2006; Burak and Fiete, 2009; Navratilova et al., 2011) and those which see grid activity as resulting from interference between multiple de-tuned neuronal oscillators (O'Keefe and Burgess, 2005; Blair et al., 2007; Burgess et al., 2007; Hasselmo et al., 2007; Giocomo and Hasselmo, 2008a; Welday et al., 2011; Hasselmo and Brandon, 2012, this issue). Attractor based models 
provide a good account of some of the properties of grid cells, for example, the incremental steps in scale and apparently fixed phase offset between neighboring cells (Barry et al., 2007; Fyhn et al., 2007). This class of model requires a precise pattern of recurrent connectivity which would presumably have to be learnt in early life, and has yet to be identified in the medial entorhinal cortex. It is possible though that the necessary connectivity may be located in other brain regions, potentially the pre or parasubiculum. Alternatively it may be spatially localized, for example, being limited to the dense entorhinal cell islands (Burgalossi et al., 2011) and thus be hard to detect. For a detailed review of the relative merits of recurrent models of grid cell formation and oscillatory interference models see Giocomo et al. (2011b).

The oscillatory interference framework was first proposed as model of place cell activity with a place field described as the envelope of an interference pattern generated between two neuronal oscillators (O'Keefe and Recce, 1993; Lengyel et al., 2003). The lower frequency component oscillates at theta frequency and the higher frequency component increases in frequency above this proportionate with the animal's running speed (see Figure 2C). Spikes are emitted at the peaks of the carrier which is the combined activity of the two oscillators and has the mean frequency of the two component waves. Thus, spikes exhibit phase precession relative to the slower frequency theta oscillation (see Figure 2D). Though intended as a model of place cell activity, grid cells provide a more natural target for this type of model, the multiple regular fields of the grid lattice arising as the oscillators move repeatedly into and out of phase. Extension of the model to grid cells requires the addition of one or more velocity controlled oscillators (VCOs), the frequency of which tracks the animal's velocity in a preferred direction. So, the model consists of a single baseline oscillator and multiple (between two and six) VCOs with preferred directions that lie at increments of $60^{\circ}$ to each other (O'Keefe and Burgess, 2005; Burgess et al., 2007) (see Figure 2E). The scale of grids generated by the model is determined by the difference in frequency between the baseline oscillator and the higher frequency VCOs; a large difference resulting in smaller spacing between firing fields of grid cells and vice versa. Early versions of the model supposed that the multiple oscillators required to form a grid might be present within individual stellate cells (Burgess et al., 2007). However, modeling shows this is unlikely as oscillators arranged in this way would quickly entrain each other (Remme et al., 2010), subsequent formulations of the model place the VCOs in individual cells upstream of the grid cells (Zilli and Hasselmo, 2010).

The interference model has found support from a number of directions. In the first instance, entorhinal layer II stellate cells exhibit sub-threshold membrane potential oscillations (MPOs) with frequencies in the theta-band (Alonso and Klink, 1993) and have been proposed as one of the components of the model (O'Keefe and Burgess, 2005; Burgess et al., 2007). These cells have been labeled after juxtacellular recording in moving rats, confirming that stellate cells do exhibit grid-like firing and are likely to be the layer II grid cells previously recorded with extracellular electrodes (Burgalossi et al., 2011). Second, a gradient in the frequency of the MPOs as well as the resonance of stellate cells has been shown to exist along the dorsal-ventral axis of the medial entorhinal cortex (Giocomo et al., 2007). This gradient mirrors grid scale which increases along the same axis (Hafting et al., 2005; Barry et al., 2007); this relationship is predicted by the model. MPO and resonance frequency is partly determined by the composition of the HCN channel, the HCN1 subunit being differentially expressed along the dorsal-ventral axis (Giocomo and Hasselmo, 2008b). Mice with the HCN1 subunit knocked out exhibit a reduction in the frequency of the MPOs as well as a flattening of the frequency gradient (Giocomo and Hasselmo, 2009). Significantly, grids recorded from these mice are of a larger scale than those found in wild type mice, indicating a causal link between the intrinsic frequency of neurons and the spatial firing of grid cells (Giocomo et al., 2011a). However, the relationship may be more complex than initially assumed because the dorsalventral gradient in grid scale was not flattened in the same way the frequency gradient was. Third, the model requires VCOs that track an animal's velocity, their firing frequency being modulated in the theta-band but increasing with the speed of travel along a preferred firing direction. Bursting theta cells with these properties, specifically a cosine-like directional tuning and speed modulation, have been found in the medial septum as well as the hippocampus and anterior thalamus (Welday et al., 2011). Finally, the model explicitly requires theta-band oscillations to generate grid firing, though once established firing may be maintained by sensory input from environmental cues, such as boundaries (Hartley et al., 2000; Burgess et al., 2007; Solstad et al., 2008). Accordingly, inactivation of the medial septum, which abolishes theta-band modulation in the entorhinal cortex, caused grid cells to temporarily lose their spatial firing, the grid lattice being reinstated when theta returns (Brandon et al., 2011; Koenig et al., 2011).

A possible criticism of the model is that the level of temporal precision necessary to maintain stable spatial firing is beyond that which can be expected of a biological system (Burak and Fiete, 2009; Zilli et al., 2009). Simulations suggest this is not the case, while independent realistically noisy oscillators would quickly decohere, a population of coupled oscillators would not (Zilli and Hasselmo, 2010; Welday et al., 2011). Furthermore, work by Fernandez and White (Soc. Neurosci. Abstr. 766.19, 2011) demonstrates that correlated excitatory and inhibitory synaptic background noise increases firing rate modulation to sinusoidal input which could help to maintain stable firing of grid cells. Recently, recordings from the medial entorhinal cortex of crawling fruit bats have added to the debate. These animals exhibit grid-like spatial firing in the absence of theta-band modulation of the cells' spike trains or of the hippocampal and entorhinal LFP (Yartsev et al., 2011). It remains to be seen if species specific differences, the unnatural nature of the foraging task, or possibly the low firing rate of the bat grid cells themselves might account for this discrepancy with the rodent data.

\section{GRID EXPANSION, THETA RHYTHM, AND ENVIRONMENTAL NOVELTY}

It has been known for some time that when an animal enters a novel environment place cells remap; place fields change their relative positions and rates (Muller and Kubie, 1987; Bostock et al., 1991; Karlsson and Frank, 2008). Conditions that provoke place 
cell remapping also cause grid firing to shift and rotate relative to the environment but not relative to grids of the same scale (Fyhn et al., 2007). Now, several new studies suggest a potential link between these phenomena and cholinergic signaling of novelty (Acquas et al., 1996; Thiel et al., 1998; Giovannini et al., 2001). Entorhinal recordings show that when a rat first enters a novel environment the regular grid lattice expands and becomes less regular (Barry et al., Soc. Neurosci. Abstr. 101.25, 2009), these effects occur in addition to the previously reported realignment. Individual fields increase in size and move further apart, at the same time becoming less circular and conform less well to a hexagonal structure. With repeated exposure to the environment the grid returns to the scale seen in a familiar environment, becoming more regular at the same time. The initial expansion, which is typically about $40 \%$ of the familiar scale, attenuates at a decreasing rate so that the "novel" grids come to resemble "familiar" grids after about four hours of experience. Environmental novelty is known to reduce theta frequency measured from the hippocampal LFP, which exhibits a similar recovery time course (Jeewajee et al., 2008b). Similarly, the theta-band modulation of expanded grids' spike trains were found to reduce in the novel environment, as did theta measured from the entorhinal LFP (Barry et al., Soc. Neurosci. Abstr. 101.25, 2009). More specifically, the reduction in intrinsic firing frequency was found to inversely correlate with the increase in scale, indicating a causal link between entorhinal oscillations and grid firing, as posited by the oscillatory interference model.

Increased cholinergic drive, such as that resulting from environmental novelty (Acquas et al., 1996; Thiel et al., 1998; Giovannini et al., 2001), reduces hippocampal theta frequency (Givens and Olton, 1995). Might cholinergic modulation contribute to the reduction in entorhinal theta and concomitant grid expansion? The potential link between increases in acetylcholine level and decreases in oscillation frequencies is supported by cellular data on the effects of acetylcholine on stellate cell resonance frequency. As noted above, intracellular recording from stellate cells in medial entorhinal cortex allows measurement of their intrinsic frequency. In particular, the resonance frequency of these neurons can be measured by delivering a current injection with a sinusoid oscillation that progressively increases in frequency from $0 \mathrm{~Hz}$ to $20 \mathrm{~Hz}$ over $20 \mathrm{~s}$ (Haas and White, 2002; Erchova et al., 2004; Heys et al., 2010). Stellate cells in medial entorhinal cortex show a clear change in amplitude of their membrane potential response to this current injection, increasing amplitude as frequency increases to theta frequencies, and then decreasing thereafter. In contrast, neurons in the lateral entorhinal cortex show a decrease in oscillation amplitude across the full range of frequencies (Shay et al., 2011). In recent experiments, the resonance frequency of stellate cells was measured before and during application of the cholinergic agonist carbachol (Heys et al., 2010). These experiments showed a clear decrease in the resonance frequency of stellate cells in the presence of carbachol. This decrease in resonance frequency appears to arise from a cholinergic reduction in the magnitude of the hyperpolarization activated cation current (h current), as shown by voltage clamp studies with carbachol in these same cells (Heys and Hasselmo, Soc. Neurosci. Abstr. 730.09, 2011).
This decrease in resonance frequency could underlie the decrease in the intrinsic frequency of theta modulation of grid cells in novel environments (Barry et al., Soc. Neurosci. Abstr. 101.25, 2009). In addition to the decrease in the intrinsic resonance frequency, application of carbachol also decreased the resonance strength in stellate cells, which is consistent with reports from Barry et al. (Soc. Neurosci. Abstr. 101.25, 2009) demonstrating a decrease in the theta-band modulation of the grids' spike train. The reduction of intrinsic frequency could also contribute to the reduction in network theta frequency in the LFP. Cholinergic modulation of other cellular properties could also contribute to the change in network oscillations, as cholinergic modulation has been shown to induce oscillations in the hippocampus in interneurons in lacunosum-moleculare (Chapman and Lacaille, 1999) as well as interneurons in stratum oriens that synapse in lacunosum-moleculare (Lawrence et al., 2006). Cholinergic modulation also regulates rhythmicity in GABAergic cells of the medial septum projecting to the hippocampus (Alreja et al., 2000).

What then is the utility of reduced theta frequency and why should this occur in response to environmental novelty? One proposed function of the theta rhythm is to provide a distinction between the circuit dynamics of encoding and retrieval (Hasselmo et al., 2002); reducing interference between patterns being learnt and those already stored (see Figure 3 ). In this model, the encoding of new information involves a strong influence of external afferent input on cortical structures including the hippocampus and entorhinal cortex as well as neocortical regions (Hasselmo et al., 2002). In the hippocampus, this is consistent with the strong current sinks in stratum lacunosum-moleculare during the peak of theta recorded in the cell body layer (Brankack et al., 1993). Furthermore, studies of LTP show that stimulation delivered at this same phase are most effective at producing potentiation (Huerta and Lisman, 1995; Holscher et al., 1997; Orr et al., 2001; Hyman et al., 2003). In contrast, the opposite phase of theta is

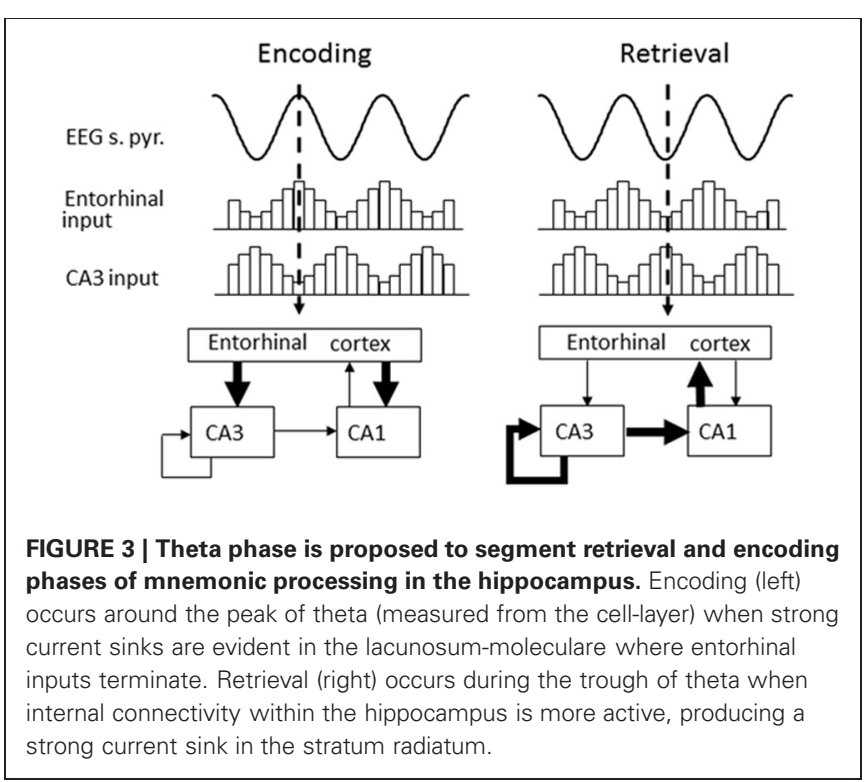


proposed to play a role in retrieval. In this phase, the internal connections of the hippocampus cause a stronger current sink in stratum radiatum (Brankack et al., 1993), and stimulation on this phase (the trough of theta in stratum pyramidale) causes long-term depression instead of LTP. Thus, this model proposes a rapid transition between encoding and retrieval during individual cycles of theta (Hasselmo et al., 2002), but at the same time slower changes in acetylcholine levels may shift the overall tone of the network more toward encoding. Such a shift is consistent with unit recording studies that have shown a change in the phase of spiking with novel stimuli (Manns et al., 2007) or in novel environments (Lever et al., 2010). In fact, a possible mechanism for the shift may be an increase in the duration of the encoding phase of the theta cycle, which would allow more effective encoding and arise from the decrease in theta frequency observed in novel environments (Jeewajee et al., 2008a,b; Barry et al., Soc. Neurosci. Abstr. 101.25, 2009).

In addition to moving the network toward a state that favors encoding, increased cholinergic modulation may, as we have described, provoke the increase in grid scale seen in novel environments. Grid expansion is likely to induce a mismatch between the expanded firing pattern of grid cells and the more stable activity of other sensory inputs to the hippocampus, such as entorhinal boundary vector cells, which do not remap or expand in novel environments (Solstad et al., 2008; Lever et al., 2009), see also (Burgess et al., 2007; Burgess, 2008). Additionally, because grids of different native scales appear to expand by differing amounts (Barry et al., Soc. Neurosci. Abstr. 101.25, 2009) they may also produce a mismatch relative to one another (see Figure 4). This differential expansion may occur if populations of grid cell or VCOs exhibit different sensitivity to acetylcholine [e.g., Shulz et al. (2000)], alternatively it might simply be a product of local variations in the concentration of extracellular acetylcholine. A further source of mismatch may be the realignment of different scaled grids which occurs between distinct environments (Fyhn et al., 2007). Together these effects would result in a significant change in the medial entorhinal input to the hippocampus, essentially orthogonalizing the pattern of activity being presented to CA3 and CA1. It seems possible then that this change would drive remapping of the hippocampal place cells, causing a new

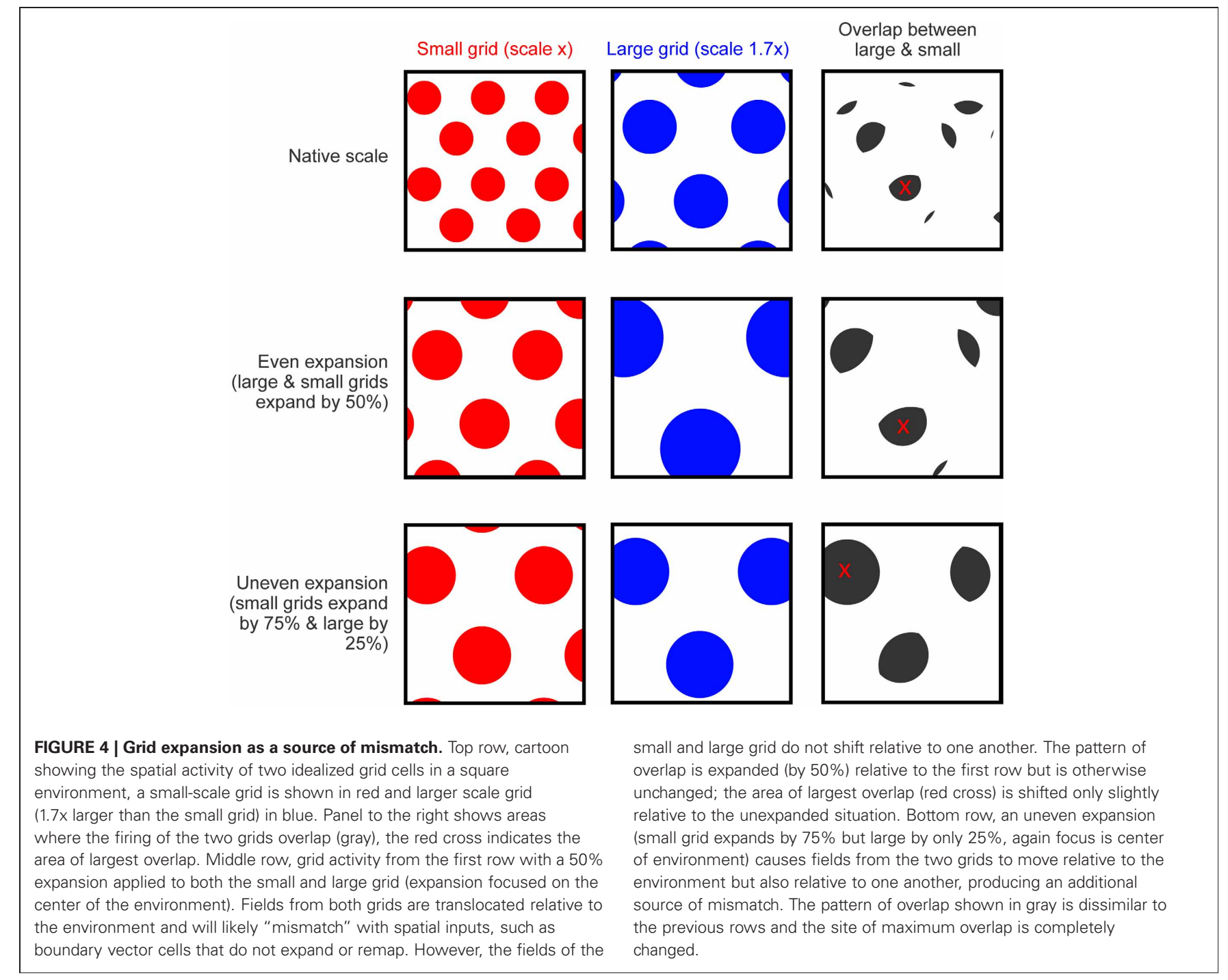


representation to be formed for the current environment. This view is supported by a recent computational study showing that distinct patterns of hippocampal activity could be generated by shifted or expanded grid inputs (Monaco and Abbott, 2011). As well as initiating hippocampal remapping, the orthogonalized input would also enhance the dynamics of encoding: Because the expanded pattern of entorhinal activity is distinct from stored patterns encoding familiar environments interference produced by inappropriate retrieval would be reduced further (Hasselmo et al., 2002; Hasselmo, 2005). After the initial expansion, subsequent exposure to a novel environment produces an incremental reduction in grid scale until, after several days, grids are the same size as those in a familiar environment (Barry et al., Soc. Neurosci. Abstr. 101.25, 2009). This contraction is accompanied by a gradual increase in theta frequency from the LFP and grid spike trains (Jeewajee et al., 2008b; Barry et al., Soc. Neurosci. Abstr. 101.25, 2009), and presumably is mediated by a reduction in cholinergic drive from the medial septum, which also attenuates with familiarity (Thiel et al., 1998). Unlike the sudden increase in scale provoked by environmental novelty, the gradual reversion to a native scale does not cause hippocampal remapping, although place fields do exhibit a slight reduction in scale with experience (Karlsson and Frank, 2008; Barry et al., Soc. Neurosci. Abstr. 101.25, 2009). It seems likely that the slower rate of change in the latter case does not generate a mismatch signal, possibly providing time for slow plastic processes to update the mapping between entorhinal grids and hippocampal place cells (Lever et al., 2002).

We have described a circuit for the detection and encoding of novelty, in particular environmental novelty, in which cholinergic modulation of theta frequency both triggers and augments the formation of new memories. In response to novel stimuli, cholinergic signaling from the medial septum to the

\section{REFERENCES}

Acquas, E., Wilson, C., and Fibiger, H. C. (1996). Conditioned and unconditioned stimuli increase frontal cortical and hippocampal acetylcholine release: effects of novelty, habituation, and fear. J. Neurosci. 16, 3089-3096.

Adams, S. V., Winterer, J., and Muller, W. (2004). Muscarinic signaling is required for spike-pairing induction of long-term potentiation at rat Schaffer collateral-CA1 synapses. Hippocampus 14, 413-416.

Aigner, T. G., and Mishkin, M. (1986). The effects of physostigmine and scopolamine on recognition memory in monkeys. Behav. Neurosci. 45, 81-87.

Alonso, A., and Klink, R. (1993). Differential electroresponsiveness of stellate and pyramidal-like cells of medial entorhinal cortex layer II. J. Neurophysiol. 70, 128-143.

Alreja, M., Wu, M., Liu, W., Atkins, J. B., Leranth, C., and Shanabrough, M. (2000). Muscarinic tone sustains

entorhinal cortex and hippocampus is augmented (Acquas et al., 1996). Increased cholinergic tone causes a reduction in the frequency of theta-band oscillations in the hippocampal formation (Givens and Olton, 1995), a state which may favor encoding and likely contributes to the expansion and reorganization of grid firing seen in novel environments (Fyhn et al., 2007; Barry et al., Soc. Neurosci. Abstr. 101.25, 2009). In turn, this immediate and pronounced change in grid cell activity is expected to push the entorhinal input to the hippocampus away from previously learnt states, instigating remapping, and supporting accurate encoding (Hasselmo et al., 2002). This dynamic mechanism is consistent with the established view of acetylcholine as an important controller of mnemonic function and fits with the mechanisms that have already been proposed to support this role, for example, the enhancement of LTP (Blitzer et al., 1990; Huerta and Lisman, 1995; Patil et al., 1998; Adams et al., 2004), elevation of feedforward over feedback connectivity (Hasselmo and Bower, 1992; Gil et al., 1997), and maintenance of input patterns (Hasselmo and Stern, 2006). Similarly, existing research (Huerta and Lisman, 1995; Holscher et al., 1997; Hyman et al., 2003), in particular computational modeling (Hasselmo et al., 2002), suggests a role for hippocampal theta in the segmentation of encoding and retrieval. The mechanism proposed here builds on those existing ideas and demonstrates how they may be tailored to an animal's current conditions, for example, biasing the efficacy of encoding when confronted with a new or changed environment.

\section{ACKNOWLEDGMENTS}

This work was supported by ONR MURI award N000141010936 and NIH R01 MH61492 and R01 MH60013, USA. Caswell Barry additionally supported by the Wellcome Trust and EU SPACEBRAIN.

spatial cognition: properties of a lateralized homing pigeon hippocampus. Rev. Neurosci. 17, 17-28.

Blair, H. T., Welday, A. C., and Zhang, K. (2007). Scale-invariant memory representations emerge from moire interference between grid fields that produce theta oscillations: a computational model. J. Neurosci. 27, 3211-3229.

Bland, B. H. (1986). The physiology and pharmacology of hippocampalformation theta rhythms. Prog. Neurobiol. 26, 1-54.

Blitzer, R. D., Gil, O., and Landau, E. M. (1990). Cholinergic stimulation enhances long-term potentiation in the CA1 region of rat hippocampus. Neurosci. Lett. 119, 207-210.

Blokland, A., Honig, W., and Raaijmakers, W. G. M. (1992). Effects of intra-hippocampal scopolamine injections in a repeated spatial acquisition task in the rat. Psychopharmacology 109, 373-376.

Boccara, C. N., Sargolini, F., Thoresen, V. H., Solstad, T., Witter, M. P.,
Moser, E. I., and Moser, M. B. (2010). Grid cells in pre- and parasubiculum. Nat. Neurosci. 13, 987-994.

Bostock, E., Muller, R. U., and Kubie, J. L. (1991). Experience-dependent modifications of hippocampal place cell firing. Hippocampus 1, 193-206.

Brandon, M. P., Bogaard, A. R., Libby, C. P., Connerney, M. A., Gupta, K., and Hasselmo, M. E. (2011). Reduction of theta rhythm dissociates grid cell spatial periodicity from directional tuning. Science 332, 595-599.

Brankack, J., Stewart, M., and Fox, S. E. (1993). Current source density analysis of the hippocampal theta rhythm: associated sustained potentials and candidate synaptic generators. Brain Res. 615, 310-327.

Brazhnik, E. S., Muller, R. U., and Fox, S. E. (2003). Muscarinic blockade slows and degrades the locationspecific firing of hippocampal pyramidal cells. J. Neurosci. 23, 611-621. 
Brocher, S., Artola, A., and Singer, W. (1992). Agonists of cholinergic and noradrenergic receptors facilitate synergistically the induction of long-term potentiation in slices of rat visual cortex. Brain Res. 573, 27-36.

Bunce, J. G., Sabolek, H. R., and Chrobak, J. J. (2004). Intraseptal infusion of the cholinergic agonist carbachol impairs delayed-nonmatch-to-sample radial arm maze performance in the rat. Hippocampus 14, 450-459.

Burak, Y., and Fiete, I. R. (2009). Accurate path integration in continuous attractor network models of grid cells. PLoS Comput. Biol. 5, e1000291. doi: 10.1371/journal.pcbi.1000291

Buresova, O., Bolhuis, J. J., and Bures, J. (1986). Differential effects of cholinergic blockade on performance of rats in the water tank navigation task and in a radial water maze. Behav. Neurosci. 100, 476-482.

Burgalossi, A., Herfst, L., von Heimendahl, M., Forste, H., Haskic, K., and Schmidt, M. B. M. (2011). Microcircuits of functionally identified neurons in the rat medial entorhinal cortex. Neuron 70, 773-786.

Burgess, N. (2008). Grid cells and theta as oscillatory interference: theory and predictions. Hippocampus 18, 1157-1174.

Burgess, N., Barry, C., and O'Keefe, J. (2007). An oscillatory interference model of grid cell firing. Hippocampus 17, 801-812.

Burgess, N., Recce, M., and O'Keefe, J. (1994). A model of hippocampal function. Neural Netw. 7, 1065-1081.

Buzsaki, G. (1989). Two-stage model of memory trace formation: a role for "noisy" brain states. Neuroscience 31, 551-570.

Buzsaki, G. (2002). Theta oscillations in the hippocampus. Neuron 33, 325-340.

Cantero, J. L., Atienza, M., Stickgold, R., Kahana, M. J., Madsen, J. R., and Kocsis, B. (2003). Sleepdependent theta oscillations in the human hippocampus and neocortex. J. Neurosci. 23, 10897-10903.

Chapman, C. A., and Lacaille, J. C. (1999). Cholinergic induction of theta-frequency oscillations in hippocampal inhibitory interneurons and pacing of pyramidal cell firing. J. Neurosci. 19, 8637-8645.

Cole, A. E., and Nicoll, R. A. (1984). Characterization of a slow cholinergic postsynaptic potential recorded in vitro from rat hippocampal pyramidal cells. J. Physiol. 352, 173-188.

Doeller, C. F., Barry, C., and Burgess, N. (2010). Evidence for grid cells in a human memory network. Nature 463, 657-661.

Easton, A., Fitchett, A. E., Eacott, M. J., and Baxter, M. G. (2011). Medial septal cholinergic neurons are necessary for context-place memory but not episodic-like memory. Hippocampus 21, 1021-1027.

Ekstrom, A. D., Kahana, M. J., Caplan, J. B., Fields, T. A., Isham, E. A., Newman, E. L., and Fried, I (2003). Cellular networks underlying human spatial navigation. Nature 425, 184-188.

Elvander, E., Schott, P. A., Sandin, J., Bjelke, B., Kehr, J., Yoshitake, T., and Ogren, S. O. (2004). Intraseptal muscarinic ligands and galanin: influence on hippocampal acetylcholine and cognition. Neuroscience 126, 541-557.

Erchova, I., Kreck, G., Heinemann, U., and Herz, A. V. (2004). Dynamics of rat entorhinal cortex layer II and III cells: characteristics of membrane potential resonance at rest predict oscillation properties near threshold. J. Physiol. 560, 89-110.

Esclassan, F., Coutureau, E., Di Scala, G., and Marchand, A. R. (2009). A cholinergic-dependent role for the entorhinal cortex in trace fear conditioning. J. Neurosci. 29, 8087-8093.

Fischer, Y., Gahwiler, B. H., and Thompson, S. M. (1999). Activation of intrinsic hippocampal theta oscillations by acetylcholine in rat septo-hippocampal cocultures. J. Physiol. 519(Pt 2), 405-413.

Foster, T. C., and Deadwyler, S. A. (1992). Acetylcholine modulates averaged sensory evoked responses and perforant path evoked field potentials in the rat dentate gyrus. Brain Res. 587, 95-101.

Freund, T. F., and Antal, M. (1988). GABA-containing neurons in the septum control inhibitory interneurons in the hippocampus. Nature 336, 170-173.

Fuhs, M. C., and Touretzky, D. S. (2006). A spin glass model of path integration in rat medial entorhinal cortex. J. Neurosci. 26, 4266-4276.

Fyhn, M., Hafting, T., Treves, A., Moser, M. B., and Moser, E. I. (2007). Hippocampal remapping and grid realignment in the entorhinal cortex. Nature 446, 190-194.

Fyhn, M., Molden, S., Witter, M. P., Moser, E. I., and Moser, M. B. (2004). Spatial representation in the entorhinal cortex. Science 305, 1258-1264.
Gais, S., and Born, J. (2004). Low acetylcholine during slow-wave sleep is critical for declarative memory consolidation. Proc. Natl. Acad. Sci. U.S.A. 101, 2140-2144.

Geisler, C., Robbe, D., Zugaro, M. Sirota, A., and Buzsaki, G. (2007) Hippocampal place cell assemblies are speed-controlled oscillators. Proc. Natl. Acad. Sci. U.S.A. 104, 8149-8154.

Ghoneim, M. M., and Mewaldt, S. P. (1975). Effects of diazepam and scopolamine on storage, retrieval and organizational processes in memory. Psychopharmacologia 44, 257-262.

Gil, Z., Conners, B. W., and Amitai, Y. (1997). Differential regulation of neocortical synapses by neuromodulators and activity. Neuron 19 679-686.

Giocomo, L. M., and Hasselmo, M. E. (2008a). Computation by oscillations: implications of experimental data for theoretical models of grid cells. Hippocampus 18, 1186-1199.

Giocomo, L. M., and Hasselmo, M. E. (2008b). Time constants of h current in layer II stellate cells differ along the dorsal to ventral axis of medial entorhinal cortex. $J$. Neurosci. 28, 9414-9425.

Giocomo, L. M., and Hasselmo, M. E. (2009). Knock-out of HCN1 subunit flattens dorsalventral frequency gradient of medial entorhinal neurons in adult mice. J. Neurosci. 29, 7625-7630.

Giocomo, L. M., Hussaini, S. A., Zheng, F., Kandel, E. R., Moser, M. B., and Moser, E. I. (2011a). Grid cells use HCN1 channels for spatial scaling. Cell 147, 1159-1170.

Giocomo, L. M., Moser, M. B., and Moser, E. I. (2011b). Computational models of grid cells. Neuron 71, 589-603.

Giocomo, L. M., Zilli, E. A., Fransen, E., and Hasselmo, M. E. (2007) Temporal frequency of subthreshold oscillations scales with entorhinal grid cell field spacing. Science 315 , 1719-1722.

Giovannini, M. G., Rakovska, A., Benton, R. S., Pazzagli, M., Bianchi, L., and Pepeu, G. (2001). Effects of novelty and habituation on acetylcholine, GABA, and glutamate release from the frontal cortex and hippocampus of freely moving rats. Neuroscience 106, 43-53.

Givens, B., and Olton, D. S. (1994). Local modulation of basal forebrain: effects on working and reference memory. J. Neurosci. 14, 3578-3587.

Givens, B., and Olton, D. S. (1995). Bidirectional modulation of scopolamine-induced working memory impairment by muscarinic activation of the medial septal area. Neurobiol. Learn. Mem. 63, 269-276.

Givens, B. S., and Olton, D. S. (1990). Cholinergic and GABAergic modulation of the medial septal area: effect on working memory. Behav. Neurosci. 104, 849-855.

Green, A., Ellis, K. A., Ellis, J., Bartholomeusz, C. F., Ilic, S., Croft, R. J., Luan Phan, K., and Nathan, P. J. (2005). Muscarinic and nicotinic receptor modulation of object and spatial n-back working memory in humans. Pharmacol. Biochem. Behav. 81, 575-584.

Haas, J. S., and White, J. A. (2002). Frequency selectivity of layer II stellate cells in the medial entorhinal cortex. J. Neurophysiol. 88, 2422-2429.

Hafting, T., Fyhn, M., Bonnevie, T., Moser, M. B., and Moser, E. I. (2008). Hippocampus-independent phase precession in entorhinal grid cells. Nature 453, 1248-1252.

Hafting, T., Fyhn, M., Molden, S., Moser, M. B., and Moser, E. I. (2005). Microstructure of a spatial map in the entorhinal cortex. Nature 436, 801-806.

Hagan, J. J., Salamone, J. D., Simpson, J., Iversen, S. D., and Morris, R. G. M. (1988). Place navigation in rats is impaired by lesions of medial septum and diagonal band but not nucleus basalis magnocellularis. Behav. Brain Res. 27, 9-20.

Hartley, T., Burgess, N., Lever, C. Cacucci, F., and O'Keefe, J. (2000). Modeling place fields in terms of the cortical inputs to the hippocampus. Hippocampus 10, 369-379.

Hasselmo, M. E. (1999). Neuromodulation: acetylcholine and memory consolidation. Trends Cogn. Sci. 3, 351-359.

Hasselmo, M. E. (2005). What is the function of hippocampal theta rhythm? - Linking behavioral data to phasic properties of field potential and unit recording data. Hippocampus 15, 936-949.

Hasselmo, M. E. (2006). The role of acetylcholine in learning and memory. Curr. Opin. Neurobiol. 16, 710-715.

Hasselmo, M. E., Anderson, B. P., and Bower, J. M. (1992). Cholinergic modulation of cortical associative memory function. J. Neurophysiol. 67, 1230-1246.

Hasselmo, M. E., Bodelon, C., and Wyble, B. P. (2002). A proposed function for hippocampal theta rhythm: separate phases of encoding 
and retrieval enhance reversal of prior learning. Neural Comput. 14, 793-817.

Hasselmo, M. E., and Bower, J. M. (1992). Cholinergic suppression specific to intrinsic not afferent fiber synapses in rat piriform (olfactory) cortex. J. Neurophysiol. 67, 1222-1229.

Hasselmo, M. E., and Bower, J. M. (1993). Acetylcholine and memory. Trends Neurosci. 6, 218-222.

Hasselmo, M. E., and Brandon, M. P. (2012). A model combining phase coding and continuous attractors for generation of grid cell firing. Front. Neural Circuits, this issue.

Hasselmo, M. E., Giocomo, L. M., and Zilli, E. A. (2007). Grid cell firing may arise from interference of theta frequency membrane potential oscillations in single neurons. Hippocampus 17, 1252-1271.

Hasselmo, M. E., and Schnell, E. (1994). Laminar selectivity of the cholinergic suppression of synaptic transmission in rat hippocampal region CA1: computational modeling and brain slice physiology. J. Neurosci. 14, 3898-3914.

Hasselmo, M. E., Schnell, E., and Barkai, E. (1995). Dynamics of learning and recall at excitatory recurrent synapses and cholinergic modulation in rat hippocampal region CA3. J. Neurosci. 15, 5249-5262.

Hasselmo, M. E., and Stern, C. E. (2006). Mechanisms underlying working memory for novel information. Trends Cogn. Sci. 10, 487-493.

Heys, J. G., Giocomo, L. M., and Hasselmo, M. E. (2010). Cholinergic modulation of the resonance properties of stellate cells in layer II of medial entorhinal cortex. J. Neurophysiol. 104, 258-270.

Holscher, C., Anwyl, R., and Rowan, M. J. (1997). Stimulation on the positive phase of hippocampal theta rhythm induces long-term potentiation that can be depotentiated by stimulation on the negative phase in area CA1 in vivo. J. Neurosci. 17, 6470-6477.

Hori, E., Tabuchi, E., Matsumura, N., Tamura, R., Eifuku, S., Endo, S., Nishijo, H., and Ono, T. (2003). Representation of place by monkey hippocampal neurons in real and virtual translocation. Hippocampus 13, 190-196.

Huerta, P. T., and Lisman, J. E. (1995). Bidirectional synaptic plasticity induced by a single burst during cholinergic theta oscillation in CA1 in vitro. Neuron 15, 1053-1063.
Huxter, J., Burgess, N., and O'Keefe, J. (2003). Independent rate and temporal coding in hippocampal pyramidal cells. Nature 425, 828-832.

Hyman, J. M., Wyble, B. P., Goyal, V., Rossi, C. A., and Hasselmo, M. E. (2003). Stimulation in hippocampal region CA1 in behaving rats yields long-term potentiation when delivered to the peak of theta and long-term depression when delivered to the trough. J. Neurosci. 23, 11725-11731.

Jeewajee, A., Barry, C., O’Keefe, J., and Burgess, N. (2008a). Grid cells and theta as oscillatory interference: electrophysiological data from freely moving rats. Hippocampus 18, 1175-1185.

Jeewajee, A., Lever, C., Burton, S., O'Keefe, J., and Burgess, N. (2008b). Environmental novelty is signaled by reduction of the hippocampal theta frequency. Hippocampus 18, 340-348.

Jensen, O., and Lisman, J. E. (2000). Position reconstruction from an ensemble of hippocampal place cells: contribution of theta phase coding. J. Neurophysiol. 83, 2602-2609.

Kahana, M. J., Sekuler, R., Caplan, J. B., Kirschen, M., and Madsen, J. R. (1999). Human theta oscillations exhibit task dependence during virtual maze navigation. Nature 399, 781-784.

Karlsson, M. P., and Frank, L. M. (2008). Network dynamics underlying the formation of sparse, informative representations in the hippocampus. J. Neurosci. 28, 14271-14281.

Kimura, F., and Baughman, R. W. (1997). Distinct muscarinic receptor subtypes suppress excitatory and inhibitory synaptic responses in cortical neurons. J. Neurophysiol. 77, 709-716.

King, C., Reece, M., and O'Keefe, J. (1998). The rhythmicity of cells of the medial septum/diagonal band of Broca in the awake freely moving rat: relationships with behaviour and hippocampal theta. Eur. J. Neurosci. 10, 464-477.

Klink, R., and Alonso, A. (1997). Muscarinic modulation of the oscillatory and repetitive firing properties of entorhinal cortex layer II neurons. J. Neurophysiol. 77, 1813-1828.

Koenig, J., Linder, A. N., Leutgeb, J. K., and Leutgeb, S. (2011). The spatial periodicity of grid cells is not sustained during reduced theta oscillations. Science 332, 592-595.
Kramis, R., Vanderwolf, C. H., and Bland, B. H. (1975). Two types of hippocampal rhythmical slow activity in both the rabbit and the rat: relations to behavior and effects of atropine, diethyl ether, urethane, and pentobarbital. Exp. Neurol. 49, 58-85.

Kremin, T., and Hasselmo, M. E. (2007). Cholinergic suppression of glutamatergic synaptic transmission in hippocampal region CA3 exhibits laminar selectivity: implication for hippocampal network dynamics. Neuroscience 149, 760-767.

Kropff, E., and Treves, A. (2008). The emergence of grid cells: intelligent design or just adaptation? Hippocampus 18, 1256-1269.

Kwag, J., and Paulsen, O. (2009). The timing of external input controls the sign of plasticity at local synapses. Nat. Neurosci. 12, 1219-1221.

Lawrence, J. J., Grinspan, Z. M., Statland, J. M., and McBain, C. J. (2006). Muscarinic receptor activation tunes mouse stratum oriens interneurones to amplify spike reliability. J. Physiol. 571, 555-562.

Lee, M. G., Chrobak, J. J., Sik, A., Wiley, R. G., and Buzsaki, G. (1994). Hippocampal theta activity following selective lesion of the septal cholinergic system. Neuroscience 62, 1033-1047.

Lengyel, M., Szatmary, Z., and Erdi, P. (2003). Dynamically detuned oscillations account for the coupled rate and temporal code of place cell firing. Hippocampus 13, 700-714.

Lever, C., Burton, S., Jeewajee, A., O'Keefe, J., and Burgess, N. (2009). Boundary vector cells in the subiculum of the hippocampal formation. J. Neurosci. 29, 9771-9777.

Lever, C., Burton, S., Jeewajee, A., Wills, T. J., Cacucci, F., Burgess, N., and O’Keefe, J. (2010). Environmental novelty elicits a later theta phase of firing in CAl but not subiculum. Hippocampus 20, 229-234.

Lever, C., Wills, T., Cacucci, F., Burgess, N., and O'Keefe, J. (2002). Longterm plasticity in hippocampal place-cell representation of environmental geometry. Nature 416, 90-94.

Madison, D. V., Lancaster, B., and Nicoll, R. A. (1987). Voltage clamp analysis of cholinergic action in the hippocampus. J. Neurosci. 7, 733-741.

Madison, D. V., and Nicoll, R. A. (1984). Control of the repetitive discharge of rat CA 1 pyramidal neurones in vitro. J. Physiol. 354, 319-331.
Manns, J. R., Zilli, E. A., Ong, K. C., Hasselmo, M. E., and Eichenbaum, H. (2007). Hippocampal CAl spiking during encoding and retrieval: relation to theta phase. Neurobiol. Learn. Mem. 87, 9-20.

Markowska, A. L., Olton, D. S., Murray, E. A., and Gaffan, D. (1989). A comparative analysis of the role of fornix and cingulate cortex in memory: rats. Exp. Brain Res. 74, 187-201.

Marrosu, F., Portas, C., Mascia, M. S., Casu, M. A., Fa, M., Giagheddu, M., Imperato, A., and Gessa, G. L. (1995). Microdialysis measurement of cortical and hippocampal acetylcholine release during sleep-wake cycle in freely moving cats. Brain Res. 671, 329-332.

McGaughy, J., Koene, R. A., Eichenbaum, H., and Hasselmo, M. E. (2005). Cholinergic deafferentation of the entorhinal cortex in rats impairs encoding of novel but not familiar stimuli in a delayed nonmatch-to-sample task. J. Neurosci. 25, 10273-10281.

McGurk, S. R., Levin, E. D., and Butcher, L. L. (1988). Cholinergicdopaminergic interactions in radial-arm maze performance. Behav. Neural Biol. 49, 234-239.

McNaughton, B. L., Battaglia, F. P., Jensen, O., Moser, E. I., and Moser, M. B. (2006). Path integration and the neural basis of the "cognitive map". Nat. Rev. Neurosci. 7, 663-678.

Mitchell, S. J., Rawlins, J. N., Steward, O., and Olton, D. S. (1982). Medial septal area lesions disrupt theta rhythm and cholinergic staining in medial entorhinal cortex and produce impaired radial arm maze behavior in rats. J. Neurosci. 2, 292-302.

Mizumori, S. J., Perez, G. M., Alvarado, M. C., Barnes, C. A., and McNaughton, B. L. (1990a). Reversible inactivation of the medial septum differentially affects two forms of learning in rats. Brain Res. 528, 12-20.

Mizumori, S. J. Y., Barnes, C. A., and Mcnaughton, B. L. (1989). Reversible inactivation of the medial septum-selective effects on the spontaneous unit-activity of different hippocampal cell-types. Brain Res. 500, 99-106.

Mizumori, S. J. Y., Barnes, C. A., and Mcnaughton, B. L. (1990b). Behavioral-correlates of theta-on and theta-off cells recorded from hippocampal-formation of mature young and aged rats. Exp. Brain Res. 80, 365-373.

Monaco, J. D., and Abbott, L. F. (2011). Modular realignment of entorhinal 
grid cell activity as a basis for hippocampal remapping. J. Neurosci. 31, 9414-9425.

Monmaur, P., Collet, A., Puma, C., Frankel-Kohn, L., and Sharif, A. (1997). Relations between acetylcholine release and electrophysiological characteristics of theta rhythm: a microdialysis study in the urethane-anesthetized rat hippocampus. Brain Res. Bull. 42, 141-146.

Muller, R. U., and Kubie, J. L. (1987). The effects of changes in the environment on the spatial firing of hippocampal complex-spike cells. J. Neurosci. 7, 1951-1968.

Muller, R. U., Kubie, J. L., and Ranck, J. B. Jr. (1987). Spatial firing patterns of hippocampal complex-spike cells in a fixed environment. J. Neurosci. 7, 1935-1950.

Navratilova, Z., Giocomo, L. M., Fellous, J. M., Hasselmo, M. E., and McNaughton, B. L. (2011). Phase precession and variable spatial scaling in a periodic attractor map model of medial entorhinal grid cells with realistic after-spike dynamics. Hippocampus [Epub ahead of print].

O'Keefe, J., and Burgess, N. (2005). Dual phase and rate coding in hippocampal place cells: theoretical significance and relationship to entorhinal grid cells. Hippocampus $15,853-866$.

O'Keefe, J., and Dostrovsky, J. (1971). The hippocampus as a spatial map. Preliminary evidence from unit activity in the freely-moving rat. Brain Res. 34, 171-175.

O'Keefe, J., and Nadel, L. (1978). The Hippocampus as a Cognitive Map. Oxford, UK: Oxford University Press.

O'Keefe, J., and Recce, M. L. (1993). Phase relationship between hippocampal place units and the EEG theta rhythm. Hippocampus 3, 317-330.

Orr, G., Rao, G., Houston, F. P., McNaughton, B. L., and Barnes, C. A. (2001). Hippocampal synaptic plasticity is modulated by theta rhythm in the fascia dentata of adult and aged freely behaving rats. Hippocampus 11, 647-654.

Patil, M. M., Linster, C., Lubenov, E., and Hasselmo, M. E. (1998). Cholinergic agonist carbachol enables associative long-term potentiation in piriform cortex slices. J. Neurophysiol. 80, 2467-2474.

Peterson, R. C. (1977). Scopolamineinduced learning failures in man. Psychopharmacologia 52, 283-289.
Rasch, B. H., Born, J., and Gais, S. (2006). Combined blockade of cholinergic receptors shifts the brain from stimulus encoding to memory consolidation. J. Cogn. Neurosci. 18, 793-802.

Rawlins, J. N., Feldon, J., and Gray, J. A. (1979). Septo-hippocampal connections and the hippocampal theta rhythm. Exp. Brain Res. 37, 49-63.

Remme, M. W., Lengyel, M., and Gutkin, B. S. (2010). Democracyindependence trade-off in oscillating dendrites and its implications for grid cells. Neuron 66, 429-437.

Rogers, J. L., and Kesner, R. P. (2003). Cholinergic modulation of the hippocampus during encoding and retrieval. Neurobiol. Learn. Mem. 80, 332-342.

Sainsbury, R. S., Heynen, A., and Montoya, C. P. (1987). Behavioral correlates of hippocampal type 2 theta in the rat. Physiol. Behav. 39, 513-519.

Shapiro, M. L., Simon, D. K., Olton, D. S., Gage, F. H. 3rd., Nilsson, O., and Bjorklund, A. (1989). Intrahippocampal grafts of fetal basal forebrain tissue alter place fields in the hippocampus of rats with fimbria-fornix lesions. Neuroscience 32, 1-18.

Shay, C. F., Boardman, I. S., James, N. M., and Hasselmo, M. E. (2011) Comparison of resonance frequency at diffeent membrane potentials in rat medial and lateral entorhinal cortex. Soc. Neurosci. Abstr. 730.12.

Shulz, D. E., Sosnik, R., Ego, V., Haidarliu, S., and Ahissar, E. (2000). A neuronal analogue of state-dependent learning. Nature 403, 549-552.

Simon, A. P., Poindessous-Jazat, F., Dutar, P., Epelbaum, J., and Bassant, M. (2006). Firing properties of anatomically identified neurons in the medial septum of anestheized and unanesthetized restrained rats. J. Neurosci. 26, 9038-9046.

Siok, C. J., Rogers, J. A., Kocsis, B., and Hajos, M. (2006). Activation of alpha7 acetylcholine receptors augments stimulation-induced hippocampal theta oscillation. Eur. J. Neurosci. 23, 570-574.

Skaggs, W. E., McNaughton, B. L., Wilson, M. A., and Barnes, C. A. (1996). Theta phase precession in hippocampal neuronal populations and the compression of temporal sequences. Hippocampus 6, 149-172.

Solstad, T., Boccara, C. N., Kropff, E., Moser, M. B., and Moser, E. I. (2008). Representation of geometric borders in the entorhinal cortex. Science 322, 1865-1868.
Stensland, H., Kirkesola, T., Moser, M. B., and Moser, E. I. (2010). Orientational geometry of entorhinal grid cells. Soc. Neurosci. Abstr. 36, 101.14.

Stewart, M., and Fox, S. E. (1990). Do septal neurons pace the hippocampal theta rhythm? Trends Neurosci. 13, 163-168.

Tang, Y., Mishkin, M., and Aigner, T. G. (1997). Effects of muscarinic blockade in perirhinal cortex during visual recognition. Proc. Natl. Acad. Sci. U.S.A. 94, 12667-12669.

Thiel, C. M., Huston, J. P., and Schwarting, R. K. (1998). Hippocampal acetylcholine and habituation learning. Neuroscience 85, 1253-1262.

Turchi, J., Saunders, R. C., and Mishkin M. (2005). Effects of cholinergic deafferentation of the rhinal cortex on visual recognition memory in monkeys. Proc. Natl. Acad. Sci. U.S.A. 102, 2158-2161.

Ulanovsky, N., and Moss, C. F. (2007) Hippocampal cellular network activity in freely moving echolocating bats. Nat. Neurosci. 10 224-233.

Vanderwolf, C. H. (1969) Hippocampal electrical activity and voluntary movement in the rat. Electroencephalogr. Clin. Neurophysiol. 26, 407-418.

Vanderwolf, C. H. (1971). Limbicdiencephalic mechanisms of voluntary movement. Psychol. Rev. 78, 83-113.

Vanderwolf, C. H. (2001). The hippocampus as an olfacto-motor mechanism: were the classical anatomists right after all? Behav. Brain Res. 127, 25-47.

Vanderwolf, C. H., Kramis, R. and Robinson, T. E. (1977) Hippocampal electrical activity during waking behaviour and sleep: analyses using centrally acting drugs. Ciba. Found. Symp. 58, 199-226.

Vogt, K. E., and Regehr, W. G. (2001) Cholinergic modulation of excitatory synaptic transmission in the CA3 area of the hippocampus. $J$. Neurosci. 21, 75-83.

Welday, A. C., Shlifer, I. G., Bloom, M. L., Zhang, K., and Blair, H. T. (2011). Cosine directional tuning of theta cell burst frequencies: evidence for spatial coding by oscillatory interference. J. Neurosci. 31, 16157-16176.

Whishaw, I. Q. (1972). Hippocampal electroencephalographic activity in the Mongolian gerbil during natural behaviours and wheel running and in the rat during wheel running and conditioned immobility. Can. J. Psychol. 26, 219-239.

Whishaw, I. Q. (1985). Cholinergic receptor blockade in the rat impairs locale but not taxon strategies for place navigation in a swimming pool. Behav. Neurosci. 99, 979-1005.

Whishaw, I. Q., and Vanderwolf, C. H. (1973). Hippocampal EEG and behavior: changes in amplitude and frequency of RSA (theta rhythm) associated with spontaneous and learned movement patterns in rats and cats. Behav. Biol. 8, 461-484.

Wilson, M. A., and McNaughton, B. L. (1994). Reactivation of hippocampal ensemble memories during sleep. Science 265, 676-679.

Winson, J. (1976). Hippocampal theta rhythmn. II. Depth profiles in the freely moving rabbit. Brain Res. 103, 71-79.

Winson, J. (1978). Loss of hippocampal theta rhythm results in spatial memory deficit in the rat. Science 201, 160-163.

Winson, J., and Abzug, C. (1977). Gating of neuronal transmission in the hippocampus: efficacy of transmission varies with behavioral state. Science 196, 1223-1225.

Winters, B. D., and Bussey, T. J. (2005). Removal of cholinergic input to perirhinal cortex disrupts object recognition but not spatial working memory in the rat. Eur. J. Neurosci. 21, 2263-2270.

Winters, B. D., Saksida, L. M., and Bussey, T. J. (2006). Paradoxical facilitation of object recognition memory after infusion of scopolamine into perirhinal cortex: implications for cholinergic system function. J. Neurosci. 26, 9520-9529.

Yartsev, M. M., Witter, M. P., and Ulanovsky, N. (2011). Grid cells without theta oscillations in the entorhinal cortex of bats. Nature 479, 103-107.

Yoder, R. M., and Pang, K. C. (2005). Involvement of GABAergic and cholinergic medial septal neurons in hippocampal theta rhythm. Hippocampus 15, 381-392.

Yun, S. H., Cheong, M. Y., Mook-Jung, I., Huh, K., Lee, C., and Jung, M. W. (2000). Cholinergic modulation of synaptic transmission and plasticity in entorhinal cortex and hippocampus of the rat. Neuroscience 97, 671-676.

Zhang, H., Lin, S. C., and Nicolelis, M. A. (2010). Spatiotemporal coupling between hippocampal acetylcholine release and theta oscillations in vivo. J. Neurosci. 30, 13431-13440. 
Zilli, E. A., and Hasselmo, M. E. (2010). Coupled noisy spiking neurons as velocity-controlled oscillators in a model of grid cell spatial firing. J. Neurosci. 30, 13850-13860.

Zilli, E. A., Yoshida, M., Tahvildari, B., Giocomo, L. M., and Hasselmo, M. E. (2009). Evaluation of the oscillatory interference model of grid cell firing through analysis and measured period variance of some biological oscillators. PLoS Comput. Biol. 5, e1000573. doi: 10.1371/journal.pcbi.1000573

Conflict of Interest Statement: The authors declare that the research was conducted in the absence of any commercial or financial relationships that could be construed as a potential conflict of interest.

Received: 09 December 2011; accepted: 02 February 2012; published online: 20 February 2012.

Citation: Barry C, Heys JG and Hasselmo ME (2012) Possible role of acetylcholine in regulating spatial novelty effects on theta rhythm and grid cells. Front. Neural Circuits 6:5. doi: 10.3389/fncir.2012.00005

Copyright (c) 2012 Barry, Heys and Hasselmo. This is an open-access article distributed under the terms of the Creative Commons Attribution Non Commercial License, which permits noncommercial use, distribution, and reproduction in other forums, provided the original authors and source are credited. 